\title{
Tertiary Amine-Mediated Polyvinyl Alcohol Membrane Over the Porous Support of Polyvinyl Chloride Membrane for $\mathrm{CO}_{2}$ Separation
}

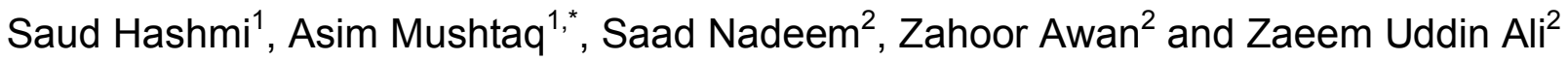 \\ ${ }^{1}$ Polymer and Petrochemical Engineering Department, NED University of Engineering \& Technology, Karachi, \\ Sindh, Pakistan \\ ${ }^{2}$ Chemical Engineering Department, NED University of Engineering \& Technology, Karachi, Sindh, Pakistan
}

\begin{abstract}
Great attention has been paid to membrane-based separation technology in various separation fields, including gas separation. It provides the benefits of energy efficiency, environmental friendliness, easy scale-up, and convenience in operation. Different division advancements are being utilized for the expulsion of acid gas carbon dioxide $\left(\mathrm{CO}_{2}\right)$. The aim of this work is to synthesis the membrane using polyvinyl alcohol (PVA) with treatment (WT) and without treatment (WOT) of the additive that is triethanolamine (TEA), to study the effect of additive on the permeance of membrane towards $\mathrm{CO}_{2}$ and the morphology changes of each membrane. In this research, virgin PVA and PVA with TEA were cast upon the porous support membrane of polyvinyl chloride (PVC). PVA was used as the polymer matrix, and TEA was used as a $\mathrm{CO}_{2}$ facilitating agent. Distilled water was used as a solvent for TEA and PVA in preparing the solution. Dimethyl acetamide (DMAc) and Tetrahydrofuran (THF) were used as solvents for PVC porous membranes. These membranes were tested on $\mathrm{CO}_{2}$ to find out the permeability and flux rates $(\mathrm{J})$. For the morphology of the membrane, we performed SEM; for thermal analysis, we performed DSC and TGA, and for the strength, we performed the tensile test. The results reveal that the presence of TEA changes the morphology and thermal behavior increases the strength and the permeability of $\mathrm{CO}_{2}$. In a nutshell, the presence of TEA enhanced the performance and the morphology of the membrane.
\end{abstract}

Keywords: Phase inversion technique, Permeance, Selectivity, Solution diffusion model, Tertiary amine, Triethanolamine.

\section{INTRODUCTION}

Ozone harming greenhouse gas carbon dioxide $\left(\mathrm{CO}_{2}\right)$ is a substance discovered principally as a primary burning of petroleum derivative also serves as a segment in landfill gas, biogas, and natural gas. The enthusiasm to eliminate $\mathrm{CO}_{2}$ from those gas streams to get fuel with upgraded energy content and forestall consumption issues in the gas transportation framework, notwithstanding $\mathrm{CO}_{2}$ suggestions to the environmental change, has driven $\mathrm{CO}_{2}$ separation measure innovation. Some of the conventional methods of natural gas purification comprise washing with chemical and physical means, that is, solvents, cryogenic distillation, and membranes. The field of membranes is getting more significant for separating $\mathrm{CO}_{2}$ from raw gas in these new times because of its simple cycle or ease of operation, the relative simplicity of activity and control, conservative, and simple to scale up as contrasted and conventional means [1,2].

Customary means, for example, adsorption and absorption for separation of $\mathrm{CO}_{2}$ from petroleum gas

\footnotetext{
"Address correspondence to this author at the Polymer and Petrochemical Engineering Department, NED University of Engineering \& Technology, Karachi, Sindh, Pakistan; Tel: +92 99261261 Ext 2419;

E-mail: engrasimmushtaq@yahoo.com
}

are commonly more energy demanding and exorbitant for both activity and upkeep. Technology and industry for separation of $\mathrm{CO}_{2}$ are more overwhelmed with polymeric materials because of their generally low assembling cost and handling capacity. But some polymer that exhibits good membrane or film-forming properties has low permeability towards gases which can be improved by using gas transport facilitating agents. The amines absorb $\mathrm{CO}_{2}$ and $\mathrm{H}_{2} \mathrm{~S}$ from sour gas. The use of amine, for example, monoethanolamine (MEA), diethanolamine (DEA), and polymers like polyvinyl amine (PVAm), polyetherimide $(\mathrm{PEI})$, are beneficial to increase the permeance and selectivity of membranes [3-5].

The use of molecular amines is more important than amine-containing polymer as they are very long molecules called chains. The mobility of chains is very slow because another molecule in their vicinity restricts them. Still, molecular amines are small in size. They have high mobility; they can diffuse in the membrane easily and absorb $\mathrm{CO}_{2}$ from the feed stream and desorb it on the permeate stream because of the pressure gradient. Primary amines have a high reaction rate with $\mathrm{CO}_{2}$, and disassociation is difficult; secondary amines have a good reversible reaction rate, while tertiary amines have a very slow reaction rate. In 1996 
Masaaki Teramoto used monoethanolamine (MEA) and diethanolamine (DEA) as a supported liquid membrane. He used $\mathrm{CO}_{2} / \mathrm{CH}_{4}$ mixture as feed, and he compared MEA and DEA-based membranes and observed increased rates of permeation for $\mathrm{CO}_{2}$ meanwhile, the reaction equilibrium constant between MEA and $\mathrm{CO}_{2}$ is quite large in the case of $\mathrm{CO}_{2}$ for release towards the reception phase quickly. The selectivity or separation factor $\alpha_{\left(\mathrm{CO}_{2} / \mathrm{CH} 4\right)}$ was about 2000. In 2006, Gil J Francisco studied the effect of different amines like 2-amino-2methyl-1-propanol (AMP), monoethanolamine (MEA), N-methyl diethanolamine (MDEA), and diethanolamine (DEA) in polyvinyl alcohol on the microporous support of polysulfone (PSF). It worked with the mixture of $\mathrm{CO}_{2}$ and $\mathrm{N}_{2}$ and observed that diethanolamine (DEA) amid the tried amines displayed an exceptional enhancement on the $\mathrm{CO}_{2}$ permeance of the membrane. The outcomes experimental findings reveal that the existence of DEA in the PVA-based membrane achieved higher permeance and improved $\mathrm{CO}_{2}$ separation than the bare PVA membrane [6-8].

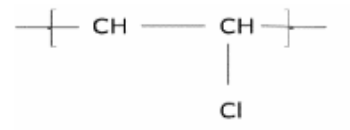

(a)

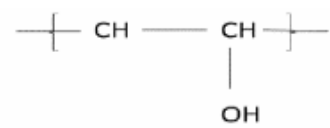

(b)

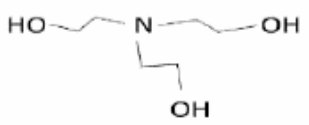

(c)

Figure 1: Structure of (a) Polyvinyl chloride, (b) Polyvinyl alcohol, (c) Triethanolamine.

In 2013, Yijie Hu studied the effect of PZ and TEA used in the blend of polyvinyl alcohol (PVA) and polyvinyl amine (PVAm) in different ratios over Polyethersulfone (PES) support. He worked with the mixture of $\mathrm{CO}_{2}$ and $\mathrm{N}_{2}$ and observed that membranes with only $\mathrm{PZ}$ have higher selectivity $\left(\mathrm{CO}_{2} / \mathrm{N}_{2}\right)$ than the
TEA in the system, and the highest selectivity $\left(\mathrm{CO}_{2} / \mathrm{N}_{2}\right)$ was observed at $67 / 33$ ratio of PZ/TEA $[9,10]$.

This research is focused on studying the effect of triethanolamine (TEA) in the PVA matrix. It is cast upon the porous support of PVC, which involves the fabrications of PVA and triethanolamine/PVA blend membrane using distilled water as a solvent on a porous PVC support membrane and then testing the membranes for the permeance towards $\mathrm{CO}_{2}$. The structures of PVA, PVC, and triethanolamine are presented in Figure 1 [4, 11-14].

\section{METHODOLOGY}

The three main constituents are polyvinyl alcohol with an average molecular weight of 124000-130000, 86-89 mole\% hydrolyzed was purchased from Chang Chun Chemicals co., Ltd, China. TEA of Industrial grade is used. PVC was purchased from Engro Polymers and Chemicals Ltd. Pakistan. Solvents, dimethylacetamide (DMAc), and tetrahydrofuran (THF) were purchased from Sigma Aldrich, with purities of $99 \%$.

\section{Sample Preparation}

Firstly, PVC solution was made, $100 \mathrm{ml}$ of DMAC and $50 \mathrm{ml}$ of tetrahydrofuran (THF) were mixed in a beaker and stirred for 15 minutes over a hot plate magnetic stirrer, and then $15 \mathrm{~g}$ of PVC was added slowly to the mixture of solvents and stirred for 5 hours. PVA solution was prepared by taking $100 \mathrm{ml}$ of distilled water, and then $10 \mathrm{~g}$ of PVA was added slowly and stirred for 7 hours. Two samples of PVA samples were made; one is plain PVA solution, and for another one, $10 \mathrm{ml}$ of TEA and $90 \mathrm{ml}$ of PVA solution were blended and stirred for 1 hour called PVA-TEA blend as depicted in Table 1.

PVC porous membrane was prepared by applying a PVC solution on the glass plate with control thickness and putting it in the distilled water bath for phase inversion, where within a few seconds, the membrane

Table 1: PVA and PVC Solution Specifications

\begin{tabular}{|c|c|c|c|c|c|c|}
\hline Sample & PVC & PVA & Distilled Water & TEA & DMAC & THF \\
\hline PVC solution & $15 \mathrm{~g}$ & - & - & - & $100 \mathrm{ml}$ & $50 \mathrm{ml}$ \\
\hline PVA solution & - & $10 \mathrm{~g}$ & $100 \mathrm{ml}$ & - & - & - \\
\hline PVA-TEA blend & - & $10 \mathrm{~g}$ & $100 \mathrm{ml}$ & $10 \mathrm{ml}$ & - & - \\
\hline
\end{tabular}


was formed. After preparing porous support, apply PVA solution on the PVC membrane for the WOT sample and PVA-TEA blend for the WT sample. Leave it at room temperature for evaporation for 12 hours to form a membrane. The procedure is given in Figure 2.

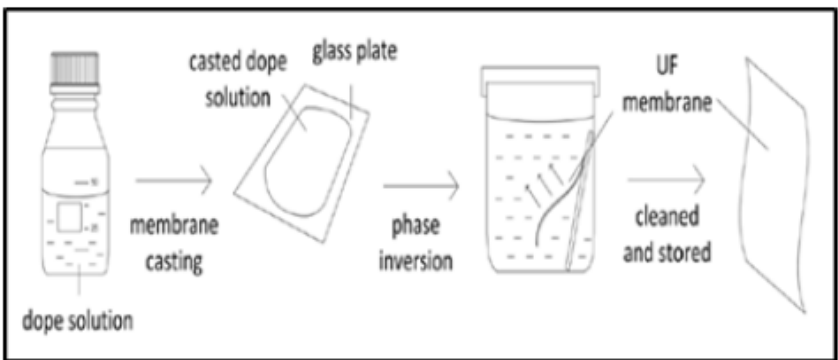

Figure 2: Phase inversion technique.

\section{Membrane Morphology}

For the morphological analysis, SEM is performed on both WT and WOT samples. SEM is performed on the SEM analyzer, JEOL from JAPAN, model no is JSM-6380A. The samples were coated up to $300^{\circ} \mathrm{A}$ with gold.

\section{Thermogravimetric Analysis}

Thermogravimetric analysis was done on the thermogravimetric analyzer of model Q600. $11.56 \mathrm{mg}$ of sample WT and $1.78 \mathrm{mg}$ of sample WOT were heated from $30^{\circ} \mathrm{C}$ to $300^{\circ} \mathrm{C}$ in the presence of $\mathrm{N}_{2}$ gas (a sweep gas) to measure the weight loss as the function of temperature.

\section{Differential Scanning Calorimetry}

The same conditions and analyzers were used for the DSC analysis, used for thermogravimetric analysis. Here, heat flow as a function of temperature was measured.

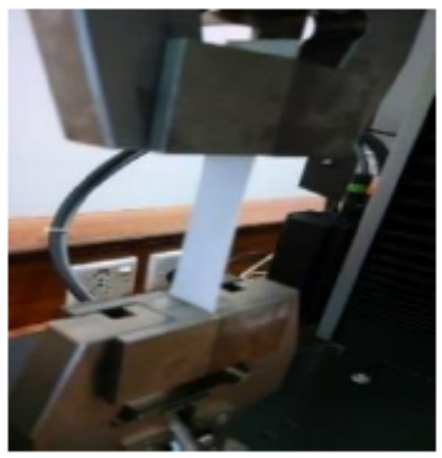

Figure 3: Specimen held in the UTM.

\section{Mechanical Properties}

For the tensile test, ASTM D882 was used. The specimen of 1 inch in breadth and 5 inches long were cut from the membrane of 35-micron thickness. The gauge length of 2 inches was used with the test speed of $25 \mathrm{~mm} / \mathrm{min}$, as portrayed in Figure 3 .

\section{Gas Permeation}

For the permeability of $\mathrm{CO}_{2}$, a membrane holder is used, shown in Figure 4. The single gas analysis was performed by measuring the flow rate of permeate through a flowmeter on different pressure ranging from 2-4 bars to calculate permeability and selectivity of the membrane, as displayed in Figure $\mathbf{5}$. The permeance of gases can be calculated from the following equation $[4,15,16]$ :

$J=P \frac{\left(P_{\text {in }}-P_{\text {out }}\right)}{l}$

where; $\mathrm{J}$ is volumetric flux in $\mathrm{cm}^{3}(\mathrm{STP}) / \mathrm{s} . \mathrm{cm}^{2}, \mathrm{P}$ is permeance in $\left(\mathrm{cm}^{3}(\mathrm{STP}) . \mathrm{cm} / \mathrm{s} \cdot \mathrm{cm}^{2} .(\mathrm{cm}\right.$ of $\left.\mathrm{Hg})\right)$, $\left(P_{i n}-P_{\text {out }}\right)$ is pressure drop across the membrane, and $\mathrm{L}$ is the thickness of the membrane in $\mathrm{cm}$. The thickness of membrane WOT is $0.0298 \mathrm{~cm}$, and WT is $0.0307 \mathrm{~cm}$.

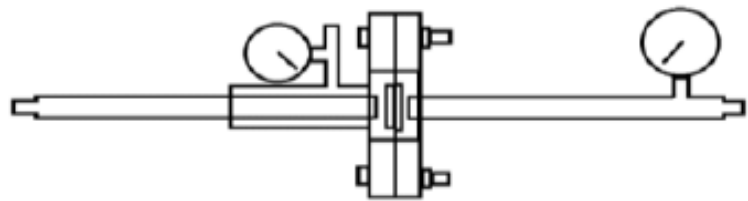

Figure 4: Membrane holder.

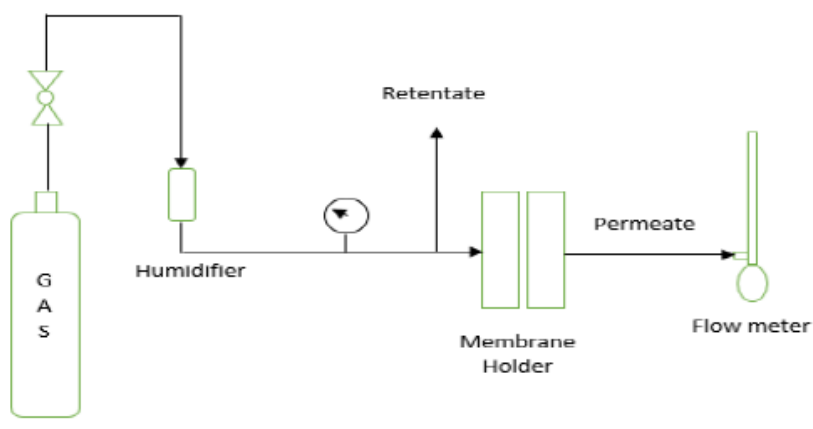

Figure 5: Gas permeation cell.

\section{RESULT AND DISCUSSION}

\section{Membrane Morphology}

The morphological analysis uses SEM, as shown in Figure 6 (a) showing a cross-sectional view of WOT 

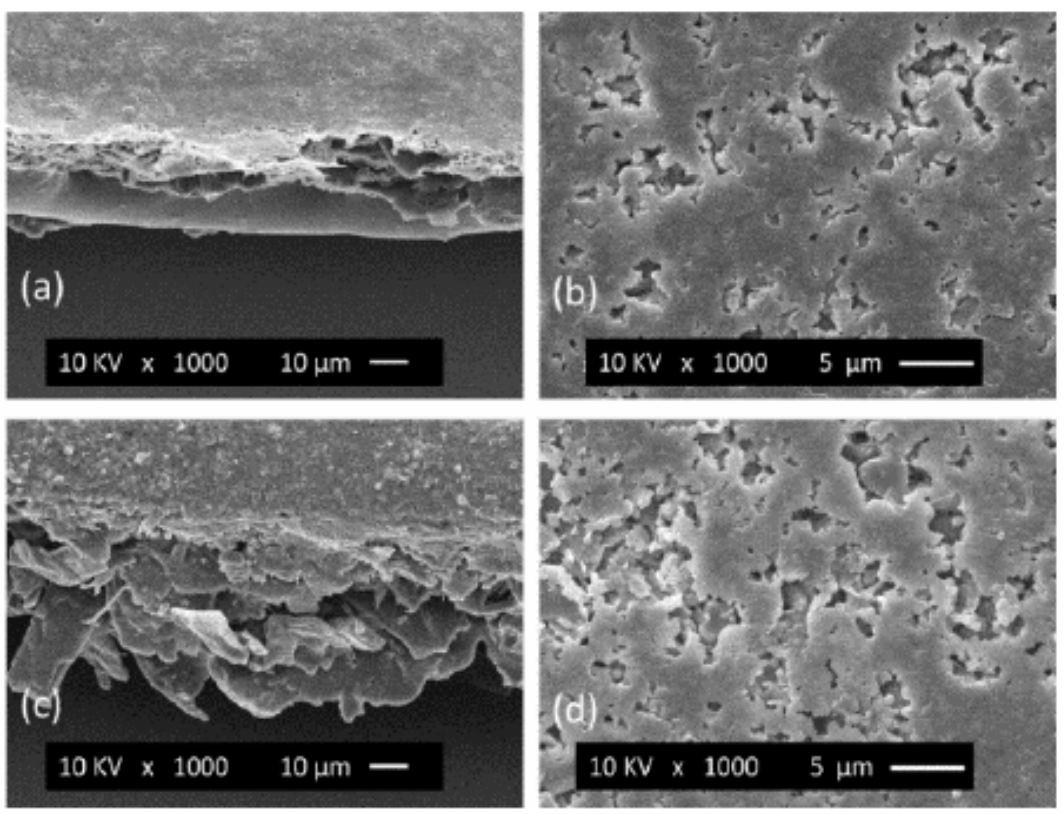

Figure 6: (a) Cross-sectional view of WOT membrane, (b) Top view of WOT membrane, (c) Cross-sectional view of WT membrane, (d) Top view of WT membrane.

membrane and Figure 6 (b) with the top view of WOT membrane. Figure 6 (c) and (d) show the crosssectional view of the WT membrane and the top view of the WT membrane, respectively. In the results for both samples, the dense layer of PVA on the porous layer of PVC, but after adding the triethanolamine, the dense layer morphology of PVA has changed a bit. The average pore size of the PVC support membrane is almost the same for both the sample that is $521 \mathrm{~nm}$ for WOT and $579 \mathrm{~nm}$ for WT.

\section{Thermogravimetric Analysis}

Figure 7 is the thermograph of both samples. It was observed that the first weight drop occurred at a lower temperature because of the presence of moisture in the

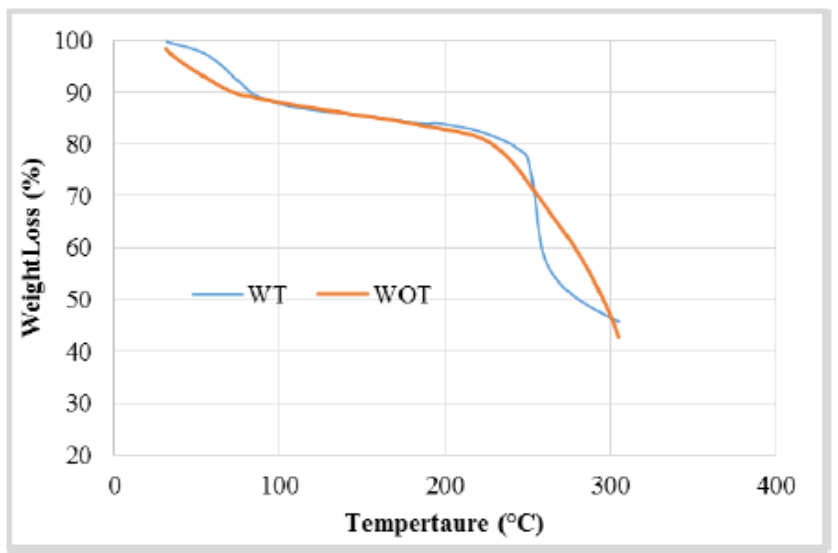

Figure 7: TGA profile of membrane with and without amine treatment.
PVA layer of the membrane. Still, later around $227^{\circ} \mathrm{C}$ measure, weight loss occurred in WOT sample. Still, this temperature increases when TEA is used in the WT membrane sample because TEA induces hydrogen bonding between the $-\mathrm{H}$ group of PVA and the $-\mathrm{OH}$ group of TEA. Now the major weight loss occurred at $250^{\circ} \mathrm{C}[8,17,18]$.

\section{Differential Scanning Calorimetry}

DSC analysis, as shown in Figure 8, portrays that the TEA enhances the glass transition temperature of the membrane. For WOT $54^{\circ} \mathrm{C}$ and WT $75^{\circ} \mathrm{C}$, the reason behind this is the induced hydrogen bonding between PVA and TEA. At $250^{\circ} \mathrm{C}$ for sample WT, TEA

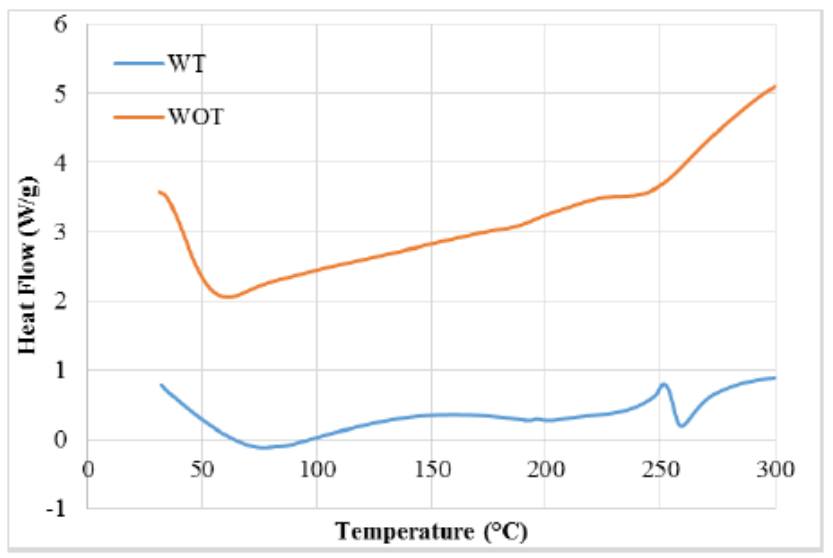

Figure 8: DSC profile of membrane with and without amine treatment. 
starts to remove from the sample. So the chains of PVA start to relax and settle down results in the induced crystallinity. Still, both the behavior that is crystallinity and removal of TEA are undesirable for the membrane performance. The melting temperature observed for WT is $260^{\circ} \mathrm{C}[18,19]$.

\section{Mechanical Test}

Results from Figure 9, as also portrayed in Table 2, shows that the addition of the TEA increases the elastic modulus to double its value, increases the tensile strength. Still, there is no significant impact of the TEA in the elongation at failure. This change is the hydrogen bonding between the $\mathrm{H}$ of PVA's backbone and $\mathrm{OH}$ of the TEA, strengthening the membrane $[3,5,12,18]$.

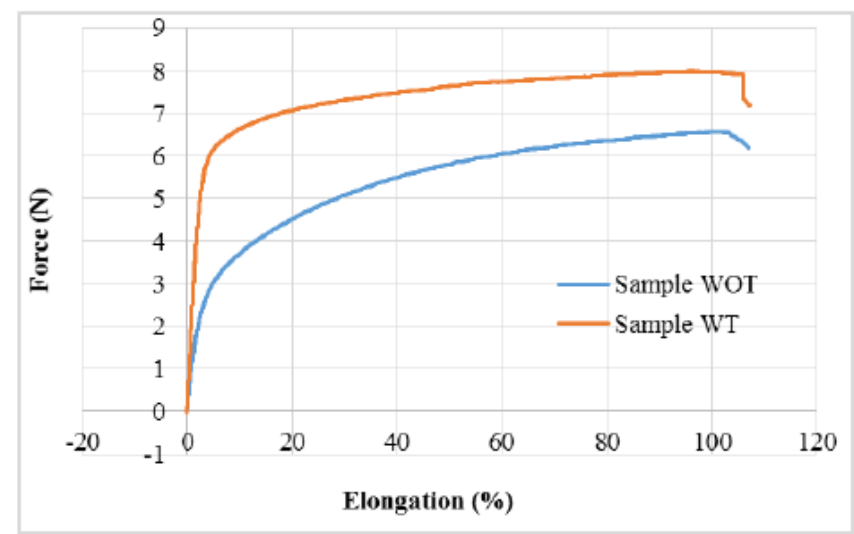

Figure 9: Tensile test of the membrane with and without amine treatment.

Table 2: Permeate Flux Versus Pressure Profile

\begin{tabular}{|c|c|c|}
\hline Property & WOT & WT \\
\hline \hline Elastic modulus (GPa) & 0.144 & 0.2945 \\
\hline Tensile strength (MPa) & 7.36 & 8.98 \\
\hline Elongation at Break (\%) & 106.9 & 107 \\
\hline
\end{tabular}

\section{Gas Permeation Test}

Permeate flux and permeability of $\mathrm{CO}_{2}$ and the effect of TEA are observed by using gas permeation cells and given in Figures 10 and 11, respectively. The following results show that the presence of TEA increases the permeability of the membrane towards $\mathrm{CO}_{2}$. The comparison for permeation test, the permeance for WOT is $3.053 \mathrm{E}-05$ $\left[\mathrm{cm}^{3}\right.$ (STP).cm/s.cm ${ }^{2}$.(cm of $\left.\left.\mathrm{Hg}\right)\right]$ and WT $5.17 \mathrm{E}-05$ $\left[\mathrm{cm}^{3}(\mathrm{STP}) . \mathrm{cm} / \mathrm{s} . \mathrm{cm}^{2}\right.$. (cm of $\left.\left.\mathrm{Hg}\right)\right]$.

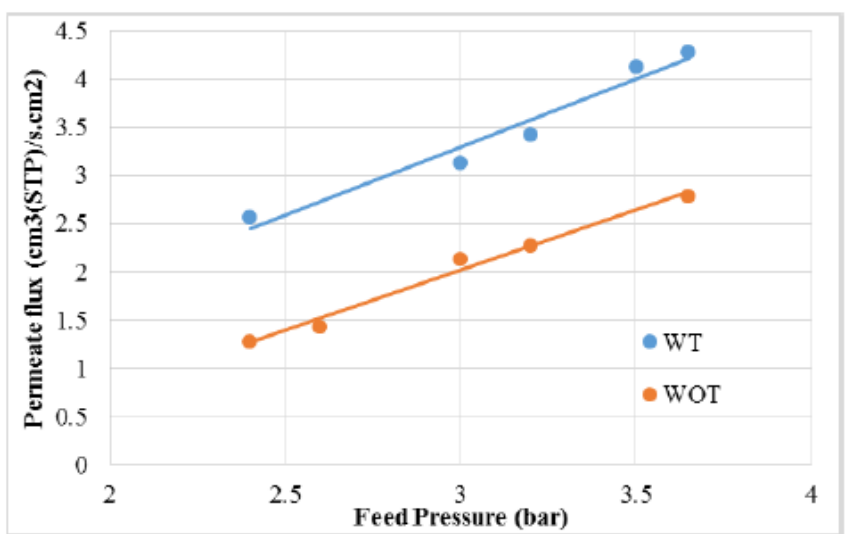

Figure 10: Result compilation for tensile test of the membrane with and without amine treatment.

A comparative analysis of the current work with the literature suggests a good improvement in $\mathrm{CO}_{2}$ permeance. Poly(amide-imide)/ $/ \mathrm{TiO}_{2}$ nanocomposite membrane for $\mathrm{CO}_{2} / \mathrm{CH}_{4}$ separation was studied and found to have a negative impact on the permeance of $\mathrm{CO}_{2}$. Matrimid 5218/ $\mathrm{TiO}_{2}$ (25 wt \%) membrane with $\mathrm{TiO}_{2}$ particles of $3 \mathrm{~nm}$ used solution casting method with Matrimid 5218 as the base and observed the $\mathrm{CO}_{2}$ permeability to be 12 Barrer with $\mathrm{TiO}_{2}$ filler at $25 \mathrm{wt} \%$. $\mathrm{PVA} / \mathrm{TiO}_{2}(20 \mathrm{wt} \%)$ membrane for gas separation with $\mathrm{TiO}_{2}$ (hydrophilic) as filler in the PES (hydrophobic ) was studied for $\mathrm{CO}_{2} / \mathrm{CH}_{4}$ separation with varying $\mathrm{TiO}_{2}$ ratios that is $(2,4,10,20) \mathrm{wt} \%$ and observed that higher $\mathrm{TiO}_{2}$ content had a detrimental effect on separation efficiency with only $\mathrm{CO}_{2}$ permeance of about 6 Barrer.

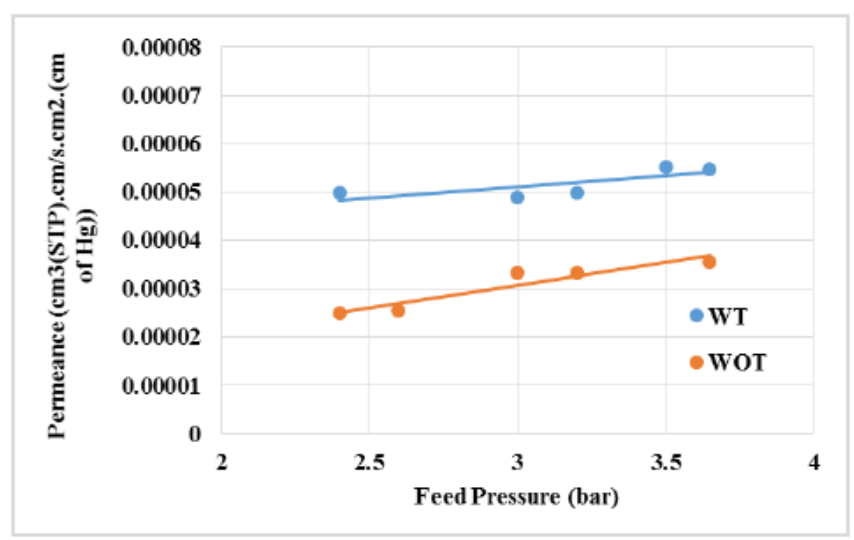

Figure 11: Permeance versus pressure profile.

The permeance of as low as $7 \times 10^{3}$ Barrer was observed by Ahmed et al. while increasing $\mathrm{TiO}_{2}$ filler level up to $20 \mathrm{wt} \%$ in PVA / $\mathrm{TiO}_{2}(20 \mathrm{wt} \%)$ membrane due to the semi-crystalline behavior of the present PVA content inside the membrane $[19,20]$. 


\section{CONCLUSION}

SEM analysis shows that the membrane consists of a dense layer of PVA over the porous layer of PVC and shows that the TEA changes the morphology of the PVA layer. Temperature, at which major weight loss occurred, increases by using TEA in the PVA layer by $23^{\circ} \mathrm{C}$. Glass transition temperature also increases for the sample with TEA by around $21^{\circ} \mathrm{C}$, and induced crystallinity is also observed $250^{\circ} \mathrm{C}$ when TEA was removed from the sample of the membrane. Tensile strength also increases by $1.62 \mathrm{MPa}$, and elastic modulus increases by $0.1505 \mathrm{GPa}$ when TEA is used in the WT sample, while there is no change observed on the elongation at break. The presence of TEA improves the permeability of $\mathrm{CO}_{2}$ through the membrane by $69.34 \%$. The temperature at which major weight loss occurred increases by using TEA in the PVA layer by $23^{\circ} \mathrm{C}$. Glass transition temperature also increases for the sample with TEA by around $21^{\circ} \mathrm{C}$, and induced crystallinity is also observed around $250^{\circ} \mathrm{C}$ when TEA was removed from the sample of the membrane. Tensile strength also increases by 1.62 $\mathrm{MPa}$, and elastic modulus increases by $0.1505 \mathrm{GPa}$ when TEA is used in the WT sample, while there is no change observed on the elongation at break. The presence of TEA improves the permeability of $\mathrm{CO}_{2}$ through the membrane by $70.0 \%$.

\section{ACKNOWLEDGEMENT}

The authors would like to acknowledge the Department of Chemical Engineering and Department of Polymer and Petrochemical Engineering, NED University of Engineering \& Technology, Karachi, Pakistan, for supporting this research work.

\section{REFERENCES}

[1] Ahmad J, Deshmukh K, Hägg MB. Influence of TiO2 on the Chemical, Mechanical, and Gas Separation Properties of Polyvinyl Alcohol-Titanium Dioxide (PVA-TiO2) Nanocomposite Membranes. Int. J. Polym. Anal. Charact. 2013; 18: 287-96. https://doi.org/10.1080/1023666X.2013.767080

[2] Bao L, Trachtenberg MC. Facilitated transport of CO2 across a liquid membrane: Comparing enzyme, amine, and alkaline. J. Membr. Sci. 2006; 280: 330-4 https://doi.org/10.1016/j.memsci.2006.01.036

[3] Zhang Y, Sunarso J, Liu S, Wang R. Current status and development of membranes for $\mathrm{CO} 2 / \mathrm{CH} 4$ separation: A review. Int J. Greenhouse Gas Control. 2013; 12: 84-107. https://doi.org/10.1016/j.ijggc.2012.10.009

[4] Maheswari AU, Palanivelu K. Carbon dioxide capture by facilitated transport membranes: a review. Int. J. Global Warming. 2017; 12: 1-49.

https://doi.org/10.1504/IJGW.2017.084013
$[5]$

Borgohain R, Mandal B. pH Responsive Carboxymethyl Chitosan/Poly(amidoamine) Molecular Gate Membrane for CO2/N2 Separation. ACS Appl. Mater. Interfaces. 2019; 11: 42616-28.

https://doi.org/10.1021/acsami.9b15044

[6] Ahmed Qamar R, Mushtaq A, Ullah A, Ali ZU. Aspen HYSYS Simulation of $\mathrm{CO} 2$ Capture for the Best Amine Solvent. J. Adv. Res. Fluid Mech. Therm Sci. 2020; 68: 124-44. https://doi.org/10.37934/arfmts.68.2.124144

[7] Francisco GJ, Chakma A, Feng X. Membranes comprising of alkanolamines incorporated into poly(vinyl alcohol) matrix for CO2/N2 separation. J. Membr. Sci. 2007; 303: 54-63. https://doi.org/10.1016/j.memsci.2007.06.065

[8] Mushtaq A, Mukhtar H, Shariff AM. Recent Development of Enhanced Polymeric Blend Membranes in Gas Separation: A Review. J. Chem. Soc. Pak. 2020; 42: 282-304. https://inis.iaea.org/search/search.aspx?orig_q=RN:5112384 4.

[9] Heydari Gorji A, Kaghazchi T. CO2/H2 separation by facilitated transport membranes immobilized with aqueous single and mixed amine solutions: Experimental and modeling study. J. Membr. Sci. 2008; 325: 40-9. https://doi.org/10.1016/j.memsci.2008.06.063

[10] Yeo ZY, Chew TL, Zhu PW, Mohamed AR, Chai S-P. Conventional processes and membrane technology for carbon dioxide removal from natural gas: A review. J. Nat. Gas Chem. 2012; 21: 282-98. https://doi.org/10.1016/S1003-9953(11)60366-6

[11] Mushtaq A, Mukhtar H, Shariff AM. Solubility Parameter Study of Polysulfone, Polyvinyl Acetate in Dimethylacetamide Solvent. J. Chem. Soc. Pak. 2019; 41: 203-6.

[12] Mushtaq A, Mukhtar $H$, Shariff AM. Properties and Characteristic of Amine-Polymer Blend Membrane. J. Chem. Soc. Pak. 2019; 41: 230-9.

[13] Yuan S, Wang Z, Qiao Z, Wang M, Wang J, Wang S. Improvement of $\mathrm{CO} 2 / \mathrm{N} 2$ separation characteristics of polyvinylamine by modifying with ethylenediamine. J. Membr. Sci. 2011; 378: 425-37.

https://doi.org/10.1016/j.memsci.2011.05.023

[14] Liang C-Y, Uchytil P, Petrychkovych R, Lai Y-C, Friess K Sipek $M$, et al. A comparison on gas separation between PES (polyethersulfone)/MMT (Na-montmorillonite) and $\mathrm{PES} / \mathrm{TiO} 2$ mixed matrix membranes. Sep. Purif. Technol. 2012; 92: 57-63. https://doi.org/10.1016/j.seppur.2012.03.016

[15] Hu Q, Marand E, Dhingra S, Fritsch D, Wen J, Wilkes G. Poly(amide-imide)/TiO2 nanocomposite gas separation membranes: Fabrication and characterization. J. Membr. Sci. 1997; 135: 65-79.

https://doi.org/10.1016/S0376-7388(97)00120-8

[16] Mushtaq A, Mukhtar H, Shariff AM. Performance Enhancement of Polymeric Blend Membranes Incorporation of Methyl Diethanol amine for $\mathrm{CO} 2 / \mathrm{CH} 4$ Separation. J. Chem. Soc. Pak. 2019; 41: 523-30.

[17] Mannan HA, Mukhtar H, Murugesan T, Nasir R, Mohshim DF, Mushtaq A. Recent Applications of Polymer Blends in Gas Separation Membranes. Chem. Eng. Technol. 2013; 36: 1838-46. https://doi.org/10.1002/ceat.201300342

[18] Low ZX, Liu Q, Shamsaei E, Zhang X, Wang H. Preparation and characterization of thin-film composite membrane with nanowire-modified support for forward osmosis process. Membranes (Basel). 2015; 5: 136-49. https://doi.org/10.3390/membranes5010136

[19] Borgohain R, Prasad B, Mandal B. Synthesis and characterization of water-soluble chitosan membrane blended with a mobile carrier for $\mathrm{CO} 2$ separation. Sep. Purif. Technol. 2019; 222: 177-87.

https://doi.org/10.1016/j.seppur.2019.04.038 
[20] Moghadam F, Omidkhah MR, Vasheghani-Farahani E, membranes. Sep. Purif. Technol. 2011; 77: 128-36. Pedram MZ, Dorosti F. The effect of TiO2 nanoparticles on https://doi.org/10.1016/j.seppur.2010.11.032 gas transport properties of Matrimid5218-based mixed matrix

Received on 08-11-2021

Accepted on 18-11-2021

Published on 24-11-2021

DOI: $\underline{\text { https://doi.org/10.15379/2410-1869.2021.08.02.02 }}$

(c) 2021 Hashmi et al.; Licensee Cosmos Scholars Publishing House.

This is an open access article licensed under the terms of the Creative Commons Attribution Non-Commercial License

(http://creativecommons.org/licenses/by-nc/3.0/), which permits unrestricted, non-commercial use, distribution and reproduction in any medium, provided the work is properly cited. 